\title{
Breeding crops to feed 10 billion
}

\author{
Lee T. Hickey ${ }^{1 \star}$, Amber Hafeez ${ }^{2}$, Hannah Robinson 3 , Scott A. Jackson $\oplus^{4}{ }^{4}$, Soraya C. M. Leal-Bertioli ${ }^{5}$, \\ Mark Tester $\oplus^{6}$, Caixia Gao $\odot^{7}$, Ian D. Godwin $\oplus^{8}$, Ben J. Hayes $\odot{ }^{1}$ and Brande B. H. Wulff ${ }^{2 \star}$
}

Crop improvements can help us to meet the challenge of feeding a population of 10 billion, but can we breed better varieties fast enough? Technologies such as genotyping, marker-assisted selection, high-throughput phenotyping, genome editing, genomic selection and de novo domestication could be galvanized by using speed breeding to enable plant breeders to keep pace with a changing environment and ever-increasing human population.

$\mathrm{O}$ ver the next 30 years, the global human population is expected to grow by $25 \%$ and reach 10 billion. Conventional breeding approaches have so far produced nutritious crops with high yields that can be harvested mechanically to meet the food needs of the growing population. But the current pace of yield increase for major crops, including wheat (Triticum aestivum), rice (Oryza sativa) and maize (Zea mays), is insufficient to meet future demand ${ }^{1,2}$. Breeders and plant scientists are under pressure to improve existing crops and develop new crops that are higher yielding, more nutritious, pest- and disease-resistant and 영 워 climate-smart.

Unlike when the first grain crops were domesticated 12,000 years ago, plant breeders today have a plethora of innovative technologies to apply in their quest for crop line improvements (Fig. 1 and Supplementary Table 1). For example, the development of automated high-throughput phenotyping systems has enabled evaluation of larger populations, which increases selection intensity and improves selection accuracy ${ }^{3}$. The advent of second- and third-generation sequencing platforms means that breeders can afford to use DNA markers to assist selections and has facilitated gene discovery, trait dissection and predictive breeding technology ${ }^{4}$. A key limiting factor for plant breeding, the long generation times of crops, which typically allow only one or two generations per year, has been alleviated by 'speed breeding' protocols that use extended photoperiods and controlled temperatures to reduce the generation times of spring wheat, barley (Hordeum vulgare), chickpea (Cicer arietinum) and canola (Brassica napus) by more than half ${ }^{5,6}$ (Table 1). Combining state-of-the-art technologies with speed breeding will underpin efforts to meet the challenge of feeding a population of 10 billion.

\section{Evolution of speed breeding}

Around 150 years ago, botanists first showed that plants can grow under artificial light using carbon arc lamps ${ }^{5}$. Shortly after, the effects of continuous light on plant growth were evaluated ${ }^{6}$. Arthur and colleagues ${ }^{7}$ reported that flowering was faster under constant light for the majority of almost 100 plant species, including vegetables, grains, weed species, herbs and garden ornamentals. In the mid-1980s, NASA partnered with Utah State University to explore the possibility of growing rapid cycling wheat under constant light on space stations. This joint effort resulted in the development of 'USU-Apogee', a dwarf wheat line bred for rapid cycling ${ }^{8}$. Meanwhile, Russian scientists proposed testing 'space mirrors' in 1993 to turn night into day and theoretically improve agricultural productivity on Earth. In 1990, the effects of light-emitting diodes (LEDs) on plant growth were evaluated at the University of Wisconsin ${ }^{9}$, and continuous improvements in LED technology ${ }^{10}$ have substantially reduced the cost of indoor plant propagation systems that increase crop productivity ${ }^{11}$.

Inspired by NASA's work, researchers at the University of Queensland coined the term 'speed breeding' in 2003 for a set of improved methods to hasten wheat breeding. Speed breeding protocols for multiple crops are now available ${ }^{12}$. Unlike doubled haploid technology, in which haploid embryos are produced and chromosomes are doubled to yield completely homozygous lines ${ }^{13,14}$, speed breeding is suitable for diverse germplasm and does not require specialized labs for in vitro culturing. The technique uses optimal light quality, light intensity, day length and temperature control to accelerate photosynthesis and flowering, coupled with early seed harvest to shorten the generation time. Specialized protocols are available for species that require specific environmental cues to induce flowering, such as vernalization or short days. When these techniques are applied to small grain cereals that can be grown at high densities-for example, 1,000 plants $/ \mathrm{m}^{2}$-the space and cost associated with developing large numbers of inbred lines can be reduced ${ }^{15}$. The combination of 'seed chipping' technology and barcoding for single plant tracking can facilitate high-throughput marker-assisted selection. To accelerate progress in plant research, activities such as crossing, development of mapping populations and adult plant phenotyping for particular traits can be performed in the speedbreeding system $^{12}$. Furthermore, speed breeding can accelerate backcrossing and pyramiding of traits $^{16}$ (Fig. 2), as well as transgenic pipelines ${ }^{12}$.

Careful planning can be used to create a pipeline of DNA marker testing, speed breeding and field evaluation. The first spring wheat variety developed using speed breeding, 'DS Faraday', was released in 2017 in Australia. In this case, speed breeding was used to

\footnotetext{
'Queensland Alliance for Agriculture and Food Innovation, The University of Queensland, Brisbane, Queensland, Australia. ${ }^{2}$ John Innes Centre, Norwich Research Park, Norwich, UK. ${ }^{3}$ InterGrain Pty Ltd, Perth, Western Australia, Australia. ${ }^{4}$ Center for Applied Genetic Technologies, Department of Crop and Soil Sciences, University of Georgia, Athens, GA, USA. ${ }^{5}$ Center for Applied Genetic Technologies, Department of Plant Pathology, University of Georgia, Athens, GA, USA. ${ }^{6}$ King Abdullah University of Science and Technology (KAUST), Division of Biological and Environmental Sciences and Engineering, Thuwal, Saudi Arabia. ${ }^{7}$ State Key Laboratory of Plant Cell and Chromosome Engineering, Center for Genome Editing, Institute of Genetics and Developmental Biology, Chinese Academy of Sciences, Beijing, China. ${ }^{8}$ School of Agriculture and Food Sciences, The University of Queensland, Brisbane, Queensland, Australia. *e-mail: I.hickey@uq.edu.au; brande.wulff@jic.ac.uk
} 


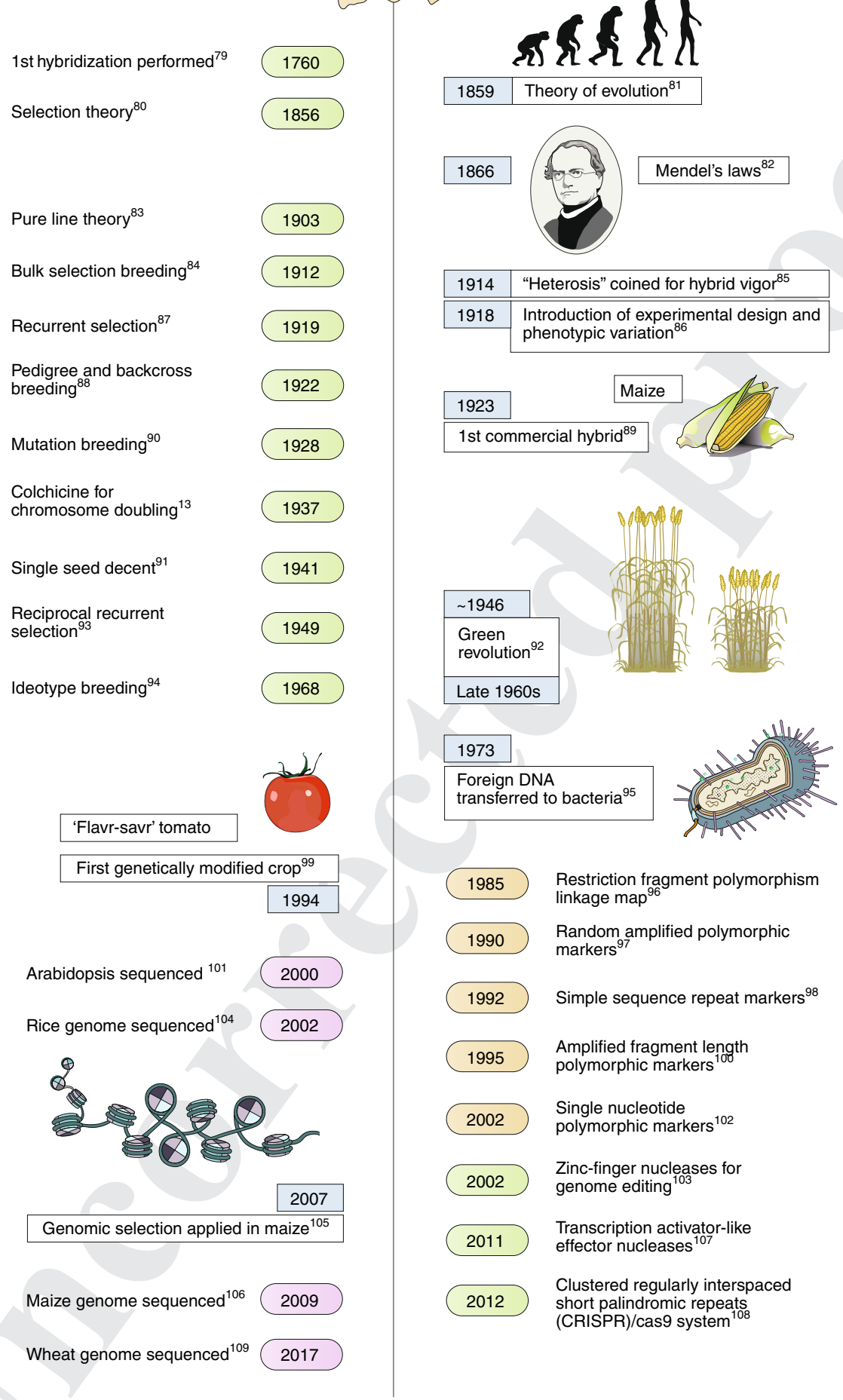

Fig. 1 | Timeline of key plant breeding techniques and technologies. A reference citation is given for each of the milestones ${ }^{13,78-109}$.

accelerate the introgression of genes for grain dormancy that inhibit germination at crop maturity to produce a high-protein milling wheat with improved tolerance to preharvest sprouting ${ }^{17}$.
For researchers who do not have access to large facilities, small, low-cost speed breeding units can be set up ${ }^{15}$. Speed breeding could also accelerate the discovery and use of allelic diversity in landraces 


\section{Table 1 | Rapid generation advance protocols for the world's top ten crops by area and production}

\begin{tabular}{|c|c|c|c|c|c|c|}
\hline Crop & Area harvested $(\mathrm{ha})^{\mathrm{a}}$ & $\begin{array}{l}\text { Production (million } \\
\text { tons) }\end{array}$ & $\begin{array}{l}\text { Field or } \\
\text { greenhouse } \\
\text { generation time }\end{array}$ & $\begin{array}{l}\text { Photoperiod } \\
\text { response }^{b}\end{array}$ & $\begin{array}{l}\text { Rapid cycling } \\
\text { generation } \\
\text { time (d) }\end{array}$ & Protocol summary \\
\hline
\end{tabular}

Q77 (d)

\begin{tabular}{llllllll}
\hline & Area & Rank & Production & Rank & & & \\
\hline Wheat & $220,107,600$ & 1 & 749 & 3 & $113^{c}$ & LD & 66 \\
& & & & & & & \\
Maize & $187,959,100$ & 2 & 1,060 & 2 & & SD & - \\
Rice & $159,807,700$ & 3 & 741 & 4 & 113 & SD & $95-105$
\end{tabular}

78-85 $\quad \mathrm{CO}_{2}(560-800$ p.p.m.) supplementation, $10 \mathrm{~h}$ light, $27^{\circ} \mathrm{C}$ day $/ 25^{\circ} \mathrm{C}$ night, 260 $\mathrm{cm}^{3}$ soil/plant ${ }^{111}$

\begin{tabular}{|c|c|c|c|c|c|c|c|}
\hline Soybean & $121,532,400$ & 4 & 335 & 6 & $102-132$ & SD & 70 \\
\hline Barley & $46,923,200$ & 5 & 141 & 11 & $110^{c}$ & LD & 63 \\
\hline Sorghum & $44,771,100$ & 6 & 64 & 24 & 119 & SD & 88 \\
\hline Rapeseed & $33,708,500$ & 7 & 69 & 21 & $123^{c}$ & LD & 113 \\
\hline Millet $^{d}$ & $31,705,500$ & 8 & 28 & 35 & $85-90$ & $\begin{array}{l}\text { Facultative or } \\
\text { obligate SD }\end{array}$ & - \\
\hline Seed cotton & $30,206,800$ & 9 & 65 & 23 & & & \\
\hline Peanut & $27,660,800$ & 10 & 44 & 29 & 140 & SD & 89 \\
\hline Sugarcane & $26,774,300$ & 11 & 1,891 & 1 & $>365$ & $\begin{array}{l}\text { LD }(12-13 \mathrm{~h} \\
\text { photoperiod } \\
\text { required for } \\
\text { flowering) }\end{array}$ & - \\
\hline Cassava & $23,482,100$ & 13 & 277 & 9 & $300-365$ & LD & - \\
\hline Oil palm fruit & $21,087,400$ & 14 & 300 & 7 & $\begin{array}{l}4 \text { years until fruit } \\
\text { maturation }\end{array}$ & ? & - \\
\hline Potato & $19,246,500$ & 15 & 377 & 5 & $138^{e}$ & LD or SD & - \\
\hline Tomato & $4,782,800$ & 37 & 177 & 10 & 80 & SD & - \\
\hline
\end{tabular}

$14 \mathrm{~h}$ light, $30^{\circ} \mathrm{C}$ day $/ 25^{\circ} \mathrm{C}$ night, $\mathrm{CO}_{2}$ supplementation (400-600 p.p.m.), increased crossing efficiency ${ }^{112}$

$22 \mathrm{~h}$ light, $22^{\circ} \mathrm{C}$ day $/ 17^{\circ} \mathrm{C}$ night, high-intensity PAR light, early seed harvest ${ }^{12,15}$

Split culm to produce both self- and cross-pollinated seeds in uni-culm sorghum; embryo rescue ${ }^{113}$

$22 \mathrm{~h}$ light, $22{ }^{\circ} \mathrm{C}$ day $/ 17^{\circ} \mathrm{C}$ night, high-intensity PAR light, early seed harvest ${ }^{12,15}$ Increased growth rate of pearl millet at $38^{\circ} \mathrm{C}$ compared to $31^{\circ} \mathrm{C}^{114}$

Light quality optimized for micropropagation $\left(B: R^{\prime}=1: 1\right)$, 12 h light ${ }^{115}$

Continuous light, $28^{\circ} \mathrm{C}$ maximum $/ 17^{\circ} \mathrm{C}$ minimum, high-intensity PAR light ${ }^{55}$

SD and continuous application of fertilizer to induce synchronous flowering ${ }^{116}$

$$
\text { - }
$$$$
-
$$

Speed breeding with extended photoperiod in development (James Hutton Institute)

Introgression of continuous light tolerance gene $C A B$ 13 to increase productivity under continuous light ${ }^{75}$

${ }^{a}$ Food and Agriculture Organization of the United Nations: http://www.fao.org/faostat/en/\#home (accessed December 2018). Area harvested was rounded to the nearest 100 ha. bSD, short day; LD, long day; DN, day neutral. cGeneration times are for spring growth habit types. 'Millet contains the following species: barnyard or Japanese millet (Echinocloa frumentacea); ragi, finger or African millet (Eleusine coracana); teff (Eragrostis abyssinica); common, golden or proso millet (Panicum miliaceum); koda or ditch millet (Paspalum scrobiculatum); pearl or cattail millet (Pennisetum glaucum); and foxtail millet

(Setaria italica). ePotato generation times are until tuber (not seed) harvest. 

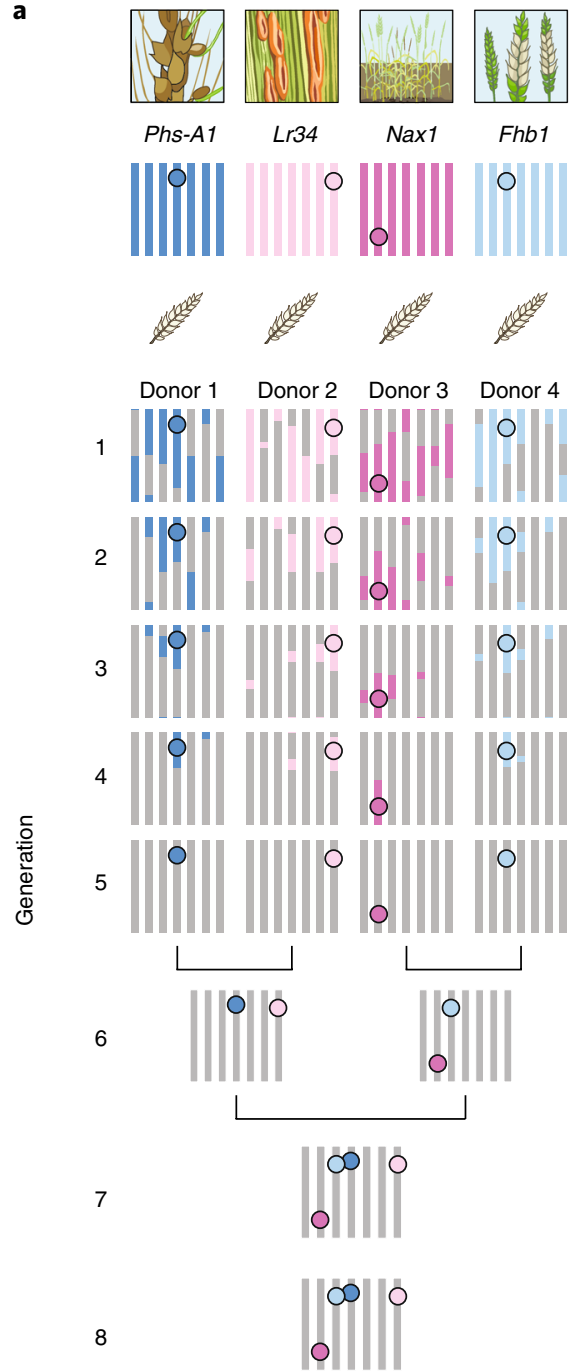

'Super wheat' with enhanced traits b

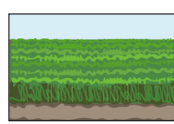

Field
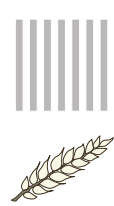

Elite variety

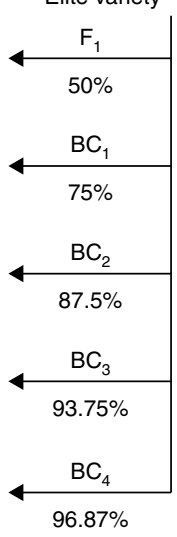

Gene stacking

Step 1

Gene stacking

Step 2

Gene stacking

Step 3

Years

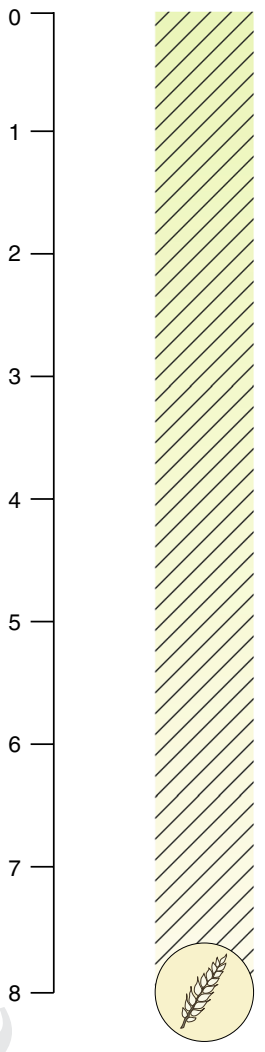

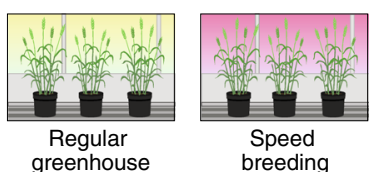

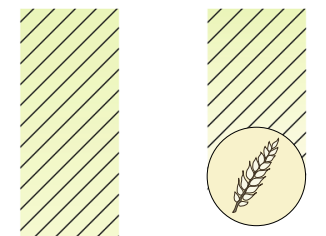

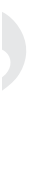

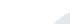

Fig. 2 | Rapid trait stacking through speed breeding and marker assisted selection. Strategy for stacking of four traits for enhanced resistance to preharvest sprouting (Phs-A1), wheat rusts ( r34), fusarium headblight (Fhb1) and salinity tolerance (Nax1) from unadapted backgrounds into an elite wheat cultivar. a, Four rounds of backcrossing and selection resulting in near isogenic lines ( $>96 \%$ pure) are combined with two rounds of crossing (gene-stacking steps 1 and 2) and selection for a homozygous line carrying all four traits (gene stacking step 3). b, The timeline to achieve the quadruple stack is shown for the field (one generation per year), a regular greenhouse (two generations per year) and a speed breeding greenhouse Q10 (six generations per year).

and in wild relatives of crops. For example, screening of the Vavilov wheat collection for resistance to leaf rust using speed breeding, together with DNA markers linked to known genes, led to the discovery of new sources of resistance ${ }^{18}$.

\section{Faster, better phenotyping}

Phenotyping refers to the measurement of any aspect of plant growth, development and physiology. The phenotype arises from interactions between genotype and environment, including fluorescence properties of the photosynthetic machinery, rates of growth, disease resistance, abiotic stress tolerance, gross morphology, phenology and, ultimately, yield components and yield. Robust phenotyping is central to plant breeding because it is the main basis for selecting lines for developing new varieties. Therefore, improvements in phenotyping methods must balance increased accuracy, speed, and cost. While the 'breeder's eye' may never be replaced, engineering can augment what the breeder sees and inform better phenotype-based choices. Innovations are manifold, including robotics to image plants (using conveyors, mobile land-based vehicles and drones) with up to hundreds of spectral bands in the visible and long wave spectrum. This enables non-destructive monitoring of plant growth and function using computer vision and machine learning, to process images and extract valuable information (traits). Our understanding of plant responses to the environment can be further informed and automated using highly connected environmental monitoring (https://www.miappe.org). Combined, these technologies present exciting opportunities to both increase phenotyping accuracy and reduce its cost. An early example of such a platform, deployed in a controlled environment, is the Plant Accelerator (https://www.plantphenomics.org.au), which still has a valuable role when addressing questions requiring controlled changes in the environment. Cheaper, field-based platforms are becoming increasingly powerful and useful, especially with easier access to drones with reasonable flight times that can carry significant payloads $^{19,20}$. The main ongoing challenge with this new generation of phenotyping remains the data handling and image processing. 
Continued contributions by computer scientists will be critical to maintain rapid advances. Together with rapid advances in genomics, better phenotyping tools are ushering in accelerated breeding schemes $^{3,21}$.

Advances in phenotyping have been made in concert with improvements in understanding phenotype-to-genotype associations using naturally occurring or laboratory-controlled population structures. For example, such methods have successfully mapped genetic regions affecting complex phenotypes such as yield components in rice $^{22}$ and height in sorghum ${ }^{23}$. Combining these technologies with genomic-assisted breeding approaches can improve crop lines more rapidly ${ }^{3,24}$.

Innovations in phenotyping of field-grown crops can only be combined with speed breeding for traits that are stable between the target environment and the conditions used in speed breeding, such as long day lengths and artificial light spectra. Phenotyping for resistance to some pests and diseases can be integrated in a speed-breeding pipeline ${ }^{16,25,26}$, as could phenotyping of simple traits such as some architectural features and ability to maintain vegetative growth in suboptimal conditions (for example, with cool days or warm nights) that might contribute to the plant's response to particular abiotic stresses ${ }^{27,28}$. Integrating speed breeding facilities with automated high-throughput phenotyping platforms ${ }^{29,30}$ will further accelerate locus and gene discovery, and the characterization of effects of specific genes on plant growth and development.

Through the use of low-cost computers ${ }^{31}$ and other hardware, phenotyping platforms are becoming cheap and accessible. And, although there are advantages to phenotyping in controlled environments, for simple disease traits, phenotyping is best confirmed in multiple field tests. For more complex traits, including drought tolerance or yield, phenotyping must be undertaken in the field in the target environment.

\section{Express editing for crop improvement}

The advantages of gene editing and GM traits could be realized sooner by incorporating these tools into a speed breeding pipeline. Many first-generation gene-editing applications rely on just one or two non-elite genotypes that are amenable to regeneration from plant tissue culture and transformation. More recently developed techniques offer high transformation efficiency even for elite genotypes ${ }^{32,33}$. Applying gene editing still requires time-consuming tissue culture, as well as specialized labs with a level of physical containment suitable for undertaking genetic manipulation using the Cas 9 gene and single guide RNA (sgRNA) sequences ${ }^{34}$. However, systems that incorporate gene editing directly in the speed breeding system, such as ExpressEdit (Fig. 3), could bypass the bottlenecks of in vitro manipulation of plant materials. Although not yet routine, many steps have been taken toward fast-tracking gene editing as outlined below.

In CRISPR gene editing, the sgRNA directs the Cas9 enzyme to the target DNA site, and Cas9 cuts the DNA at this site. 'CRISPRready' genotypes that contain a heterologous Cas9 gene can be created. For example, a transformed plant harboring a Cas 9 transgene can be used as a donor to create a range of elite inbred lines using speed marker-assisted backcrossing. As discussed below, there are different ways to deliver the sgRNA for targeted genome editing. However, this technique will still yield transgenic plants that are subject to regulation, and subsequent segregation of the edited locus from the transgene(s), Cas 9 and, in most cases, a selectable marker gene will be required.

Integrating genome editing and speed breeding without tissue culture requires a number of technological breakthroughs, with the optimal outcomes being allelic modification without tissue culture or the application of exogenous DNA, as these would avoid the genetically modified organism label (Fig. 3). It has been widely demonstrated that single or multiplex edits can be achieved $^{35}$, and this could now be implemented using the following tissue-culture-free techniques.

For example, genome editing can be done using CRISPR-Cas9 ribonucleoprotein complexes. This has been undertaken for a number of species, including wheat ${ }^{36}$, maize ${ }^{37}$ and potato (Solanum tubersosum $)^{38}$. Immature embryos or protoplasts have been used as the target tissue, and ideally this methodology would be optimized for mature seeds or germinating seedlings ${ }^{39}$. Phenotyping could be performed in subsequent generations, allowing the stacking of traits. Alternatively, clay nanosheets could be engineered to deliver the Cas 9 protein and sgRNA. Clay nanosheets can be used to deliver RNA interference (RNAi) constructs to plants to render them virus resistant ${ }^{40}$. The RNAi persists for a few weeks in planta and moves throughout the plant. Delivery of Cas 9 and sgRNA components can be achieved by using viral vectors, such as geminiviruses ${ }^{41}$ or in planta particle bombardment using shoot apical meristems of mature seeds or by biolistic DNA delivery without callus culture to get the editing machinery into cells-for example, wheat ${ }^{39}$. This could be used to deliver preassembled Cas9-sgRNA ribonucleoproteins into plant shoot apical meristems to generate gene edits or to introduce edits into pollen and inflorescence tissues.

\section{Fast-forwarding genomic selection}

Marker-assisted selection, whereby a small number of genes or traits can be tracked using linked DNA markers, has been successfully applied in almost all crop breeding programs for traits with mutations of large effect. Genomic selection, by contrast, uses genome-wide DNA markers to predict the genetic merit of breeding individuals for complex traits ${ }^{42}$. This technology was developed to understand complex traits, such as yield, that are affected by variants in a large number of genes and/or regulatory elements, typically each of which has a small effect. The effect of these variants is captured through linkage disequilibrium with the genome-wide DNA markers-for example, single nucleotide polymorphisms-and the effects of the markers are estimated in large reference or training populations, consisting of lines or individuals in which marker genotypes and the trait are measured. Once the marker effects have been estimated, candidate lines for breeding can be genotyped. Then, to assess the value of each of the candidate lines for breeding, their genomic breeding values (GEBVs) are estimated as the sum of the marker effects for the marker alleles they carry. The lines with the highest ranked GEBV can then be selected to breed the next generation. One advantage of genomic selection over traditional breeding methods is that lines can be selected and used as parents early in the variety development pipeline (Fig. 4), and multiple breeding cycles based on GEBV can be achieved in the same amount of time as a single cycle of traditional breeding was achieved previously. The potential for genomic selection to save time and resources is greatest for traits that are typically measured late in the variety development pipeline (evaluation phase, Fig. 4) and are costly to phenotype, such as yield.

Genomic selection is being used at scale in crop breeding programs in the private sector-for example, in maize breeding ${ }^{43}$. Cooper et al. $^{43}$ and Gaffney et al. ${ }^{44}$ describe the impact of industry-scale evaluations of drought-tolerant maize hybrids generated by genomic selection. Those varieties ('AQUAmax' hybrids) are now widely planted in farmers' fields. Extensive evaluation of farm production data demonstrates that AQUAmax maize hybrids have significantly greater yields under both favorable and drought stress conditions in the United States, improving yield stability in the presence of water limitation and diminishing risks for farmers ${ }^{44}$.

To achieve even greater gains, multiple traits can be simultaneously targeted using genomic selection. For example to select plants with improved yields, the accuracy of selection can be increased 


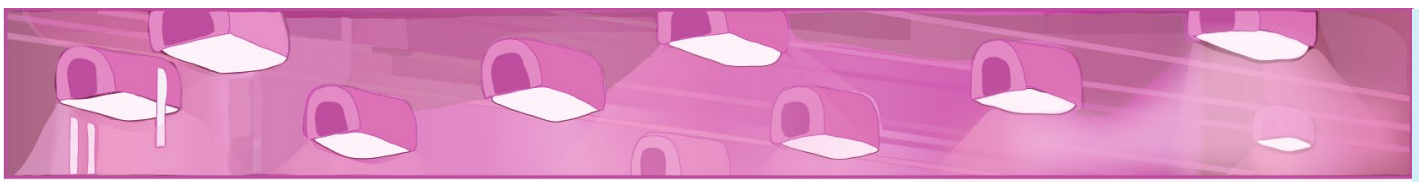

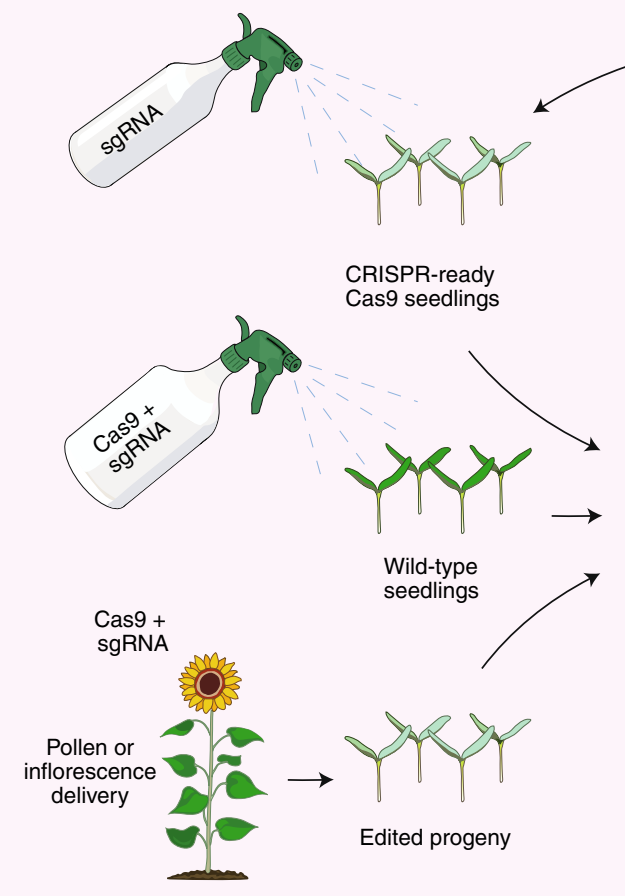

Wild-type plant

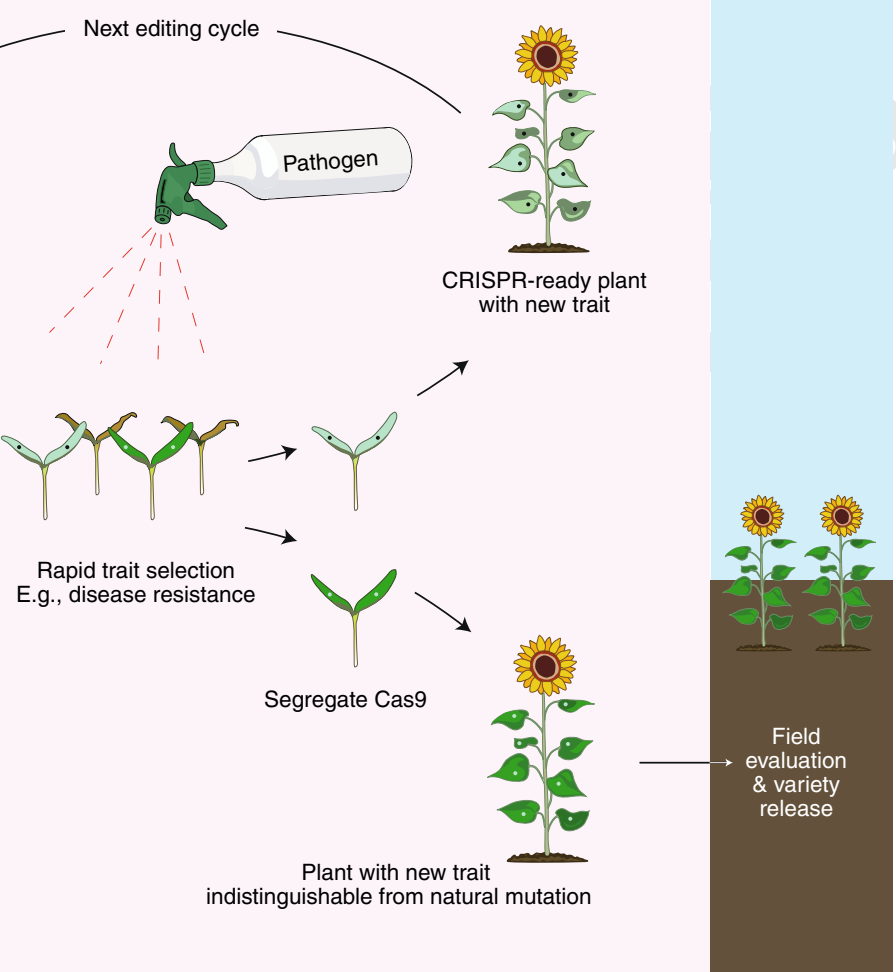

Fig. 3 ExpressEdit approaches, in which rapid genome editing can be performed directly in the speed breeding system. To avoid the bottleneck of plant regeneration in the laboratory, the Cas9 gene and sgRNA sequences can be directly applied to plants. Segregating progeny can be screened for the new trait (for example, disease resistance), and plants that lack Cas9 but carry the new trait can be identified. Alternatively, Cas9 can remain in 'CRISPR-ready' plants that can be subjected to more cycles of editing by applying sgRNA for different gene targets.

by using a multi-trait approach that includes phenotypes that can be measured at high throughput and at an early stage, such as canopy temperature and the normalized difference vegetation index, together with GEBV for yield ${ }^{45}$. Another example is enduse quality traits, which are among the last traits to be measured in wheat breeding programs. Using the multi-trait approach, enduse quality trait predictions based on near-infrared and nuclear magnetic resonance spectral analyses of small quantities of flour can be integrated with DNA marker predictions to give accurate GEBV. These values can then be used to select plants with desired end-use quality traits much earlier in the breeding cycle than is otherwise possible ${ }^{46}$.

The return from genomic selection will be greatest when combined with other technologies that (i) reduce generation intervals and (ii) include the precise location of causative mutations affecting the target trait or traits, because in this situation the predictions no longer rely on linkage disequilibrium between the DNA markers and the causative mutations. Since speed breeding can substantially reduce generation intervals ${ }^{12}$, genetic gain from this approach could be greatly increased by applying genomic selection at each generation to select the parents for the next generation. At present, the cost of genotyping is the biggest challenge for implementing genomic selection. To

Q13 reduce the costs, one option is to apply genomic selection only every second or third generation, or to select only candidates that pass thresholds for traits that can be reliably phenotyped during speed breeding cycles, such as some types of disease resistance ${ }^{25}$. New strategies for genotyping taking advantage of high-throughput sequencing, such as rAmpSeq, may dramatically reduce the cost of genotyping for genomic selection ${ }^{47}$.

The precise location of causative single nucleotide polymorphisms is unknown for many traits, although individual polymorphisms have been identified in some cases. If these polymorphisms occur in wild or non-elite germplasm, one strategy might be to adopt an ExpressEdit approach to rapidly engineer the polymorphism into elite material and then to use genomic selection to simultaneously select for the edit and the thousands of other polymorphisms affecting desired traits through genome-wide DNA markers (Fig. 4). Another promising option would be to integrate genomic selection with rapid disease-resistance gene discovery and cloning technologies ${ }^{48,49}$. While marker-assisted selection can be used to transfer resistance genes with large effects, coupling the approach with genomic selection could help to accumulate and maintain minor gene variants that contribute to effective resistance. Such an approach might reduce selection pressure for pathogen variants to overcome resistance genes.

Genomic selection could also be used to stack useful haplotypes across the genome to create an optimum cropping line from available haplotypes segregating in the population ${ }^{50}$. Genome regions could be defined by linkage disequilibrium blocks, for example. The haplotype GEBV are defined as the sum of the haplotype's marker effects. Then the haplotype with the best GEBV can be identified for each part of the genome, and these best haplotypes can be stacked in a single individual using an optimum pattern of crosses. Haplotypes 


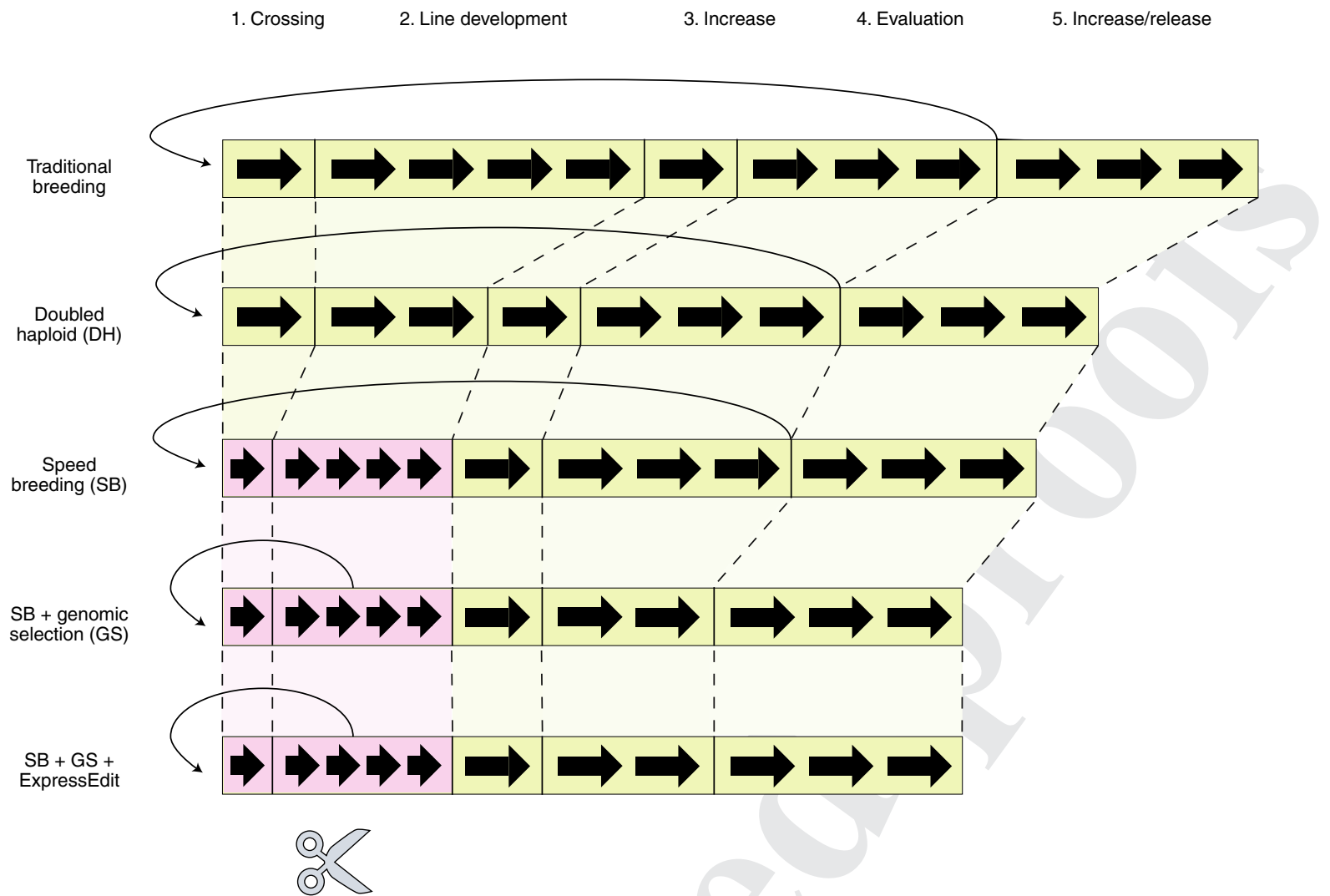

211 Fig. 4 | Breeding strategies. Visual representation of breeding strategies and comparison of cycle length for traditional breeding versus progressive

Q12 strategies that exploit doubled haploid (DH), speed breeding (SB), genomic selection (GS) and ExpressEdit (indicated by scissors). Pink shading indicates steps that are performed under speed-breeding conditions while green shading indicates steps performed under conventional conditions. Block arrows indicate a single generation. The curved arrows indicate steps in the breeding pipeline where the best lines identified by field evaluation or genomic selection are used as parents to make new crosses. Example provided for an inbred crop.

with desirable gene edits or disease resistance alleles could be set as the 'best' haplotype for a particular genomic region and combined in an ultimate individual. When combined with speed breeding, this stacking approach could be used to rapidly develop new crop varieties with high performance across multiple traits.

\section{Accelerated domestication}

Plant domestication is a lengthy process of selection for mutations in a suite of traits that eventually renders a plant cultiva$\mathrm{ble}^{51}$. Mimicking this process through neo-domestication of wild species could be an alternative way to breed modern cultivars ${ }^{52}$. This provides access to genes and traits not found in the domesticated gene pool. Domestication is often linked to polyploidy: indeed, most crops are polyploid. However, polyploidy complicates crop improvement owing to sexual isolation from relatives and polysomic inheritance ${ }^{53}$. Where polyploidy is directly linked to domestication, rapid re-domestication via re-creation of polyploids is a direct route by which to introgress novel genes and alleles from wild relatives. This re-domestication process can be accelerated with speed breeding. Peanut (Arachis hypogea) and banana (Musa spp.) are two polyploid crops that can benefit from such an approach. Peanut, an allotetraploid, can be recapitulated by crossing wild AA- and BB-genome diploids, followed by colchicine doubling of the chromosomes and several cycles of backcross and selection for agronomic traits ${ }^{54}$. Speed breeding, which works with peanut ${ }^{55}$, could accelerate re-domestication at multiple selection steps. In banana, polyploidy coincides with the domestication of various cultivars via inter- and intraspecific crosses of wild $\mathrm{AA}$ and $\mathrm{BB}$ species plus chromosome elimination and introgression from other species, resulting in seedless cultivated forms with genome constitutions of AAA, $\mathrm{AAB}$ and $\mathrm{ABB}^{56}$. The small number of foundation polyploid events combined with worldwide clonal propagation of perennial forms with little or no resistance to devastating diseases aggravates the problems caused by narrow genetic diversity ${ }^{57}$. In both peanut and banana, resynthesis of polyploid domesticates via the use of various diploid species and speed breeding would provide access to novel traits, including disease resistance, and rapid development of new varieties. Moreover, in banana, direct editing of current elite triploid cultivars could lead to interim rapid deployment of improved lines, obviating the cost and time needed to resynthesize triploids ${ }^{58,59}$.

To circumvent polysomic genetics, in some species it is possible to breed in diploids using donors with desired traits and then reconstitute the polyploid via unreduced gametes and/or interploidy crosses. This provides an attractive route to producing new varieties, as less time and fewer resources are required as compared to breeding the polyploid directly; this has been useful for a few crops, such as banana ${ }^{60}$ and potato ${ }^{61}$. In banana, for instance, breeding is carried out between diploid elite lines and wild relatives followed by hybridization of selected diploids (diploid hybrids) and chromosome doubling of selected diploids to rapidly create interploidy crosses (i.e., $4 \mathrm{x}$ by $2 \mathrm{x}$ ) for the production of seedless triploids ${ }^{62}$. Banana plants are large and cycles are long, up to three years between the creation 


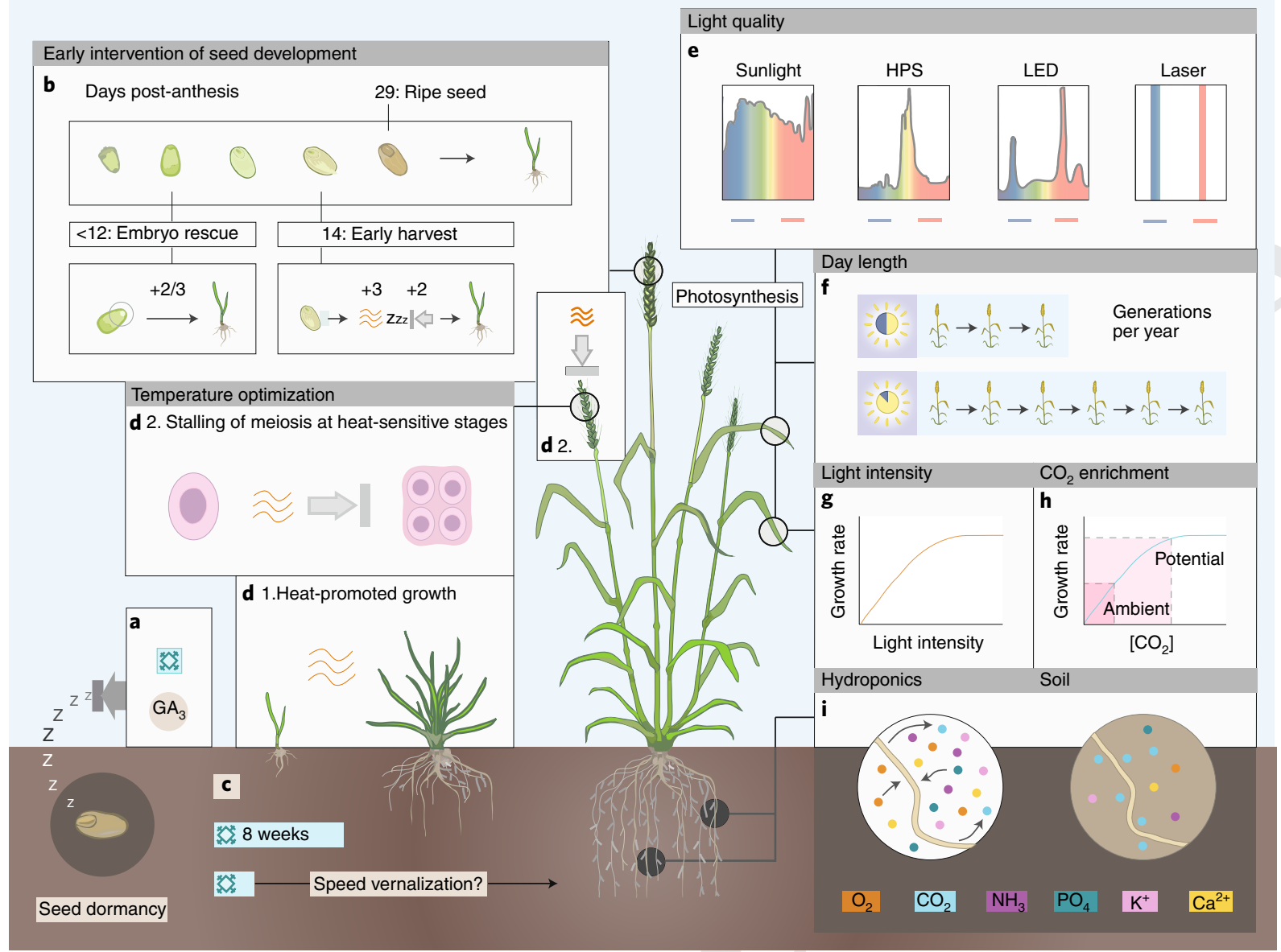

Fig. 5 | 'Supercharging' plant growth: speed breeding 2.0. a, Seed dormancy can be broken through stratification or through application of phytohormones,

Q16 such as gibberellic acid" $\left(\mathrm{GA}_{3}\right)$. b. Seed ripening can be circumvented to reduce generation time; harvesting of immature embryos saves the most time but requires in vitro culturing, while some seed (for example, wheat and barley) can be harvested early and dried before proceeding to the next generation. c) If the requirement for vernalization could be removed, this would reduce the generation time for winter crops. $\mathbf{d}$, Elevated temperatures promote plant growth (1), but high temperatures should be avoided during heat-sensitive stages to prevent stalling of development, such as during meiosis in wheat (2). e, Spectral distributions of daylight, high-pressure sodium vapor (HPS) lamp, LED and laser. Red and blue rectangles represent wavelengths that can be harnessed in plant photosynthesis. The conversion efficiency from electricity to light is given for artificial light sources. f, Increasing day length reduces the generation time for long-day and day-neutral crops. $\mathbf{g}, \mathbf{h}$, Optimization of light intensity and $\mathrm{CO}_{2}$ concentration. $\mathbf{i}$, Hydroponics can enhance growth in 17 comparison to soil, as $\mathrm{CO}_{2}$ and other deleterious solutes can be cycled away from the roots while exposing the roots to more oxygen and nutrients.

of hybrids and initial evaluation. Again, speed breeding could have a role in terms of the faster development of hybrids for evaluation and further crosses and selection .

Other routes to domestication of new species include the engineering of known domestication genes to recapitulate a domesticated plant ideotype. This has been achieved using genome editing with CRISPR-Cas9 to target domestication-related genes in orphan crops $^{63}$ and wild species ${ }^{52}$. Engineered neo-domesticates could potentially be used directly as crops or crossed with elite lines for incorporation of new traits without the time lag associated with the use of wild germplasm. This has been demonstrated for tomato ${ }^{52,64}$.

Editing and mutagenesis combined with speed breeding could also be applied to create healthier foods by biofortification-for example, increasing levels of vitamin B9 in rice or removal of deleterious proteins such as saponins from quinoa (Chenopodium quinoa), antinutritional glucosinolates from Brassica seeds, and neurotoxins from grass pea (Lathyrus sativus). Domestication by gene editing is an exciting route for rapidly tapping into the reservoir of genes in crop wild relatives by producing lines that can be directly crossed with advanced lines with little genetic drag. Combined with speed breeding, these tools provide rapid access to novel genetic variation and a means of accelerating deployment of this variation to growers' fields.

\section{Speed breeding 2.0}

Innovations in LEDs combined with extended photoperiod and early seed harvest enabled speed breeding to be more broadly applied. But what scope is there for increasing speed even further? Speed breeding aims to optimize and integrate the parameters that affect plant growth and reproduction to reduce generation times and the time taken to observe phenotypes, particularly those that manifest late in development. How can we customize speed breeding to meet the specific requirements of different crops, cultivars and phenotypes under study?

Breaking seed dormancy is the first step for intervention to improve breeding rates. In many species, the maternal plant imposes dormancy on seeds during embryogenesis. Seed dormancy can be broken immediately after harvest through cold stratification, whereby seeds are imbibed at low temperature or by applying germination-promoting hormones, such as gibberellins ${ }^{65}$ (Fig. 5a). Harvesting wheat and barley seeds early, at $14 \mathrm{~d}$ post-anthesis, followed by $3 \mathrm{~d}$ of drying and $4 \mathrm{~d}$ of cold stratification ${ }^{12}$, enables the breaking of dormancy and reduction of generation time (Fig. 5b) by 
around $15 \mathrm{~d}$ when compared with harvesting mature seeds. A similar approach has also been applied in lentil (Lens culinaris) ${ }^{66}$. Even earlier harvesting is possible by using embryo rescue; from $12 \mathrm{~d}$ post-anthesis, a germination rate of $100 \%$ can be achieved after $2-3$ $\mathrm{d}$ of culture ${ }^{67}$ (Fig. 5b). This method circumvents any need for seed drying and stratification, shortening generation time by at least $8 \mathrm{~d}$.

The transition to flowering could also be shortened. Some plants require a prolonged period of cold treatment (vernalization) to mediate the transition to flowering; winter wheat varieties require 6 to 12 weeks. The molecular components governing vernalization are known in many plants. Transiently manipulating these control points-for example, by downregulation of the central regulator VERNALISATION 2-could lead to the development of 'speed vernalization' (Fig. 5c).

Plant growth could be accelerated by raising temperature at key growth stages. High temperatures can cause water vapor deficits that hinder plant growth and pollen development; however, when permissive water vapor levels are maintained, the rate of vegetative growth and senescence can be accelerated. This has been demonstrated in maize ${ }^{68}$, although plants were susceptible to large reductions in grain yield at high minimal (night-time) temperatures. When the temperature sensitivities of plants are known, it is possible to intervene with a high temperature at appropriate growth stages to accelerate growth. In bread wheat, a temperature-sensitive period in which grain yield is reduced has been discovered during meiosis ${ }^{69}$ (Fig. 5d.ii). Therefore, a high temperature could be applied during vegetative growth while a low temperature could be maintained during reproductive stages to sustain grain development (Fig. 5d.i).

Optimizing day length and light quality could improve breeding timelines. Day length and light quality variation can accelerate plant growth (Fig. 5f). Longer days promote the growth of dayneutral or long-day plants, while light quality optimized for photosynthesis may enhance primary production. Furthermore, the ratio of red to blue light is also important for flowering ${ }^{70}$, which, in wheat, is induced earliest under pink light, where the ratio is around 1 (ref. ${ }^{71}$ ). One feature of existing speed breeding systems is the use of LEDs to improve light quality and reduce operational costs $^{12,15}$. Instead, laser light could be used to reduce costs further because it has a higher electrical conversion efficiency, with $40-60 \%$ of energy being converted into light, depending on the light color $^{72}$ (Fig. 5e). As well as boosting growth and increasing returns on energy input, laser light can be generated outside 218 a growth cabinet or greenhouse, beamed inside and then scattered over plants, eradicating much of the cooling costs that make crop research in controlled environments expensive. Arabidopsis thaliana plants grown under these conditions exhibit reduced expression of certain proteins that are associated with light and radiation stress in comparison to those grown under cool-white fluorescent light ${ }^{72}$; higher photon irradiance intensities could therefore be applied using this approach with less damage to the plant (Fig. 5g).

Soil has historically been fundamental to the success of plant husbandry. However, hydroponic growth systems allow optimization of nutrient profiles and faster uptake while maintaining the aerobic conditions optimal for root growth (Fig. 5i). Despite these potential benefits, care must be taken to optimize nutrient supply and thereby avoid adverse effects such as non-senescing leaves and 219 asynchronous maturation ${ }^{73}$.

Elevating the concentration of $\mathrm{CO}_{2}$ can promote productivity through increasing the photosynthetic capacity of plants (Fig. 5h). Increasing $\mathrm{CO}_{2}$ also raises the saturation threshold for other inputs important for photosynthesis (such as light intensity and quality), as well as offsetting water loss induced by high temperatures through reducing stomatal aperture. Equally, optimized water and nutrient supply may be required for the positive effects of elevated $\mathrm{CO}_{2}$ to be realized $^{74}$. Thus, hydroponics, where such inputs are not limiting, could unleash the full growth potential of plants.

Depending on the objective (rapid cycling, rapid crossing or rapid phenotyping) and the plant species being used, parameters will need to be optimized relative to trade-offs. For example, Zeng et al. ${ }^{67}$ applied water stress and grew plants in small, $80-\mathrm{cm}^{3}$ wells; their results were projected to allow eight generations of wheat per year, with the caveat of a low seed yield of just two or three seeds per plant.

\section{Outlook}

For some crops, gains from speed breeding and integration with other breeding technologies cannot be realized because of sensitivity to extended day length or because extra light does not accelerate time to sexual maturity. For example, tomato is sensitive to constant light, but researchers have identified a tomato gene that enables the plant to tolerate constant light, and when transferred into a variety grown under speed-breeding conditions it resulted in a $20 \%$ increase in fruit yield ${ }^{75}$. Likewise, genetic or environmental solutions could enable speed breeding in other recalcitrant crops, such as short-day species like maize and biennial species like sugar beet (Table 1). Innovations such as evaporative cooling systems that use sea water $^{76}$, semitransparent solar panels that selectively transmit wavelengths that promote plant growth ${ }^{77}$, and more efficient lighting systems (for example, laser light ${ }^{72}$ ) could reduce speed-breeding costs going forward and broaden use.

Plant breeding over the past 100 years has delivered high-yielding crops that have sustained human population growth. The development of next-generation crop varieties using a suite of modern breeding technologies will meet the demands of population growth in the decades to come.

Received: 19 August 2018; Accepted: 25 April 2019;

\section{References}

1. Ray, D. K., Ramankutty, N., Mueller, N. D., West, P. C. \& Foley, J. A. Recent patterns of crop yield growth and stagnation. Nat. Commun. 3, 1293 (2012).

2. Ray, D. K., Mueller, N. D., West, P. C. \& Foley, J. A. Yield trends are insufficient to double global crop production by 2050. PLoS One 8, e66428 (2013).

3. Araus, J. L., Kefauver, S. C., Zaman-Allah, M., Olsen, M. S. \& Cairns, J. E. Translating high-throughput phenotyping into genetic gain. Trends Plant Sci. 23, 451-466 (2018).

4. Bassi, F. M., Bentley, A. R., Charmet, G., Ortiz, R. \& Crossa, J. Breeding schemes for the implementation of genomic selection in wheat (Triticum spp.). Plant Sci. 242, 23-36 (2016).

5. Pfeiffer, N. E. Microchemical and morphological studies of effect of light on plants. Bot. Gaz. 81, 173-195 (1926).

6. Siemens, C. W. III On the influence of electric light upon vegetation, and on certain physical principles involved. Proc. R. Soc. Lond. B 30, 210-219 (1880).

7. Arthur, J. M., Guthrie, J. D. \& Newell, J. M. Some effects of artificial climates on the growth and chemical composition of plants. Am. J. Bot. 17, 416-482 (1930).

8. Bugbee, B. \& Koerner, G. Yield comparisons and unique characteristics of the dwarf wheat cultivar 'USU-Apogee'. Adv. Space Res. 20, 1891-1894 (1997).

9. Bula, R. J. et al. Light-emitting diodes as a radiation source for plants. HortScience 26, 203-205 (1991).

10. Darko, E., Heydarizadeh, P., Schoefs, B. \& Sabzalian, M. R. Photosynthesis under artificial light: the shift in primary and secondary metabolism. Philos. Trans. R. Soc. Lond. B. Biol. Sci. 369, 20130243 (2014).

11. Stutte, G. W. J. H. Commercial transition to LEDs: a pathway to high-value products. HortScience 50, 1297-1300 (2015).

12. Watson, A. et al. Speed breeding is a powerful tool to accelerate crop research and breeding. Nat. Plants 4, 23-29 (2018).

13. Blakeslee, A. F. \& Avery, A. G. Method of inducing doubling of chromosomes in plants: by treatment with colchicine. J. Hered. 28, 393-411 (1937).

14. Laurie, D. A. \& Bennett, M. D. The production of haploid wheat plants from wheat $\times$ maize crosses. Theor. Appl. Genet. 76, 393-397 (1988). 
15. Ghosh, S. et al. Speed breeding in growth chambers and glasshouses for crop breeding and model plant research. Nat. Protoc. 13, 2944-2963 (2018).

16. Hickey, L. T. et al. Speed breeding for multiple disease resistance in barley. Euphytica 213, 64 (2017).

17. Schwager, R. in The Land (Fairfax Media, 2017).

18. Riaz, A. et al. Mining Vavilov's treasure chest of wheat diversity for adult plant resistance to Puccinia triticina. Plant Dis. 101, 317-323 (2017).

19. Ziliani, G. M., Parkes, D. S., Hoteit, I. \& McCabe, F. M. Intra-season crop height variability at commercial farm scales using a fixed-wing UAV. Remote Sens. 10, 12 (2018).

20. Wang, X. et al. High-throughput phenotyping with deep learning gives insight into the genetic architecture of flowering time in wheat. Preprint at https://doi.org/10.1101/527911 (2019).

21. Tester, M. \& Langridge, P. Breeding technologies to increase crop production in a changing world. Science 327, 818-822 (2010).

22. Tanger, P. et al. Field-based high throughput phenotyping rapidly identifies genomic regions controlling yield components in rice. Sci. Rep. 7, 42839 (2017).

23. Wang, X., Singh, D., Marla, S., Morris, G. \& Poland, J. Field-based high-throughput phenotyping of plant height in sorghum using different sensing technologies. Plant Methods 14, 53 (2018).

24. Shakoor, N., Lee, S. \& Mockler, T. C. High throughput phenotyping to accelerate crop breeding and monitoring of diseases in the field. Curr. Opin. Plant Biol. 38, 184-192 (2017).

25. Riaz, A., Periyannan, S., Aitken, E. \& Hickey, L. A rapid phenotyping method for adult plant resistance to leaf rust in wheat. Plant Methods 12, 17 (2016).

26. Dinglasan, E., Godwin, I. D., Mortlock, M. Y. \& Hickey, L. T. Resistance to yellow spot in wheat grown under accelerated growth conditions. Euphytica 209, 693-707 (2016).

27. Richard, C. et al. Selection in early generations to shift allele frequency for seminal root angle in wheat. Plant Genome https://doi.org/10.3835/ plantgenome2017.08.0071 (2018).

28. Fischer, R. A. R. \& Rebetzke, G. J. Indirect selection for potential yield in early-generation, spaced plantings of wheat and other small-grain cereals: a review. Crop Pasture Sci. 69, 439-459 (2018).

29. Awlia, M. et al. High-throughput non-destructive phenotyping of traits contributing to salinity tolerance in Arabidopsis thaliana. Front. Plant Sci. 7, 1414 (2016).

30. Al-Tamimi, N. et al. Salinity tolerance loci revealed in rice using high-throughput non-invasive phenotyping. Nat. Commun. 7, 13342 (2016).

31. Tovar, J. C. et al. Raspberry Pi-powered imaging for plant phenotyping. Appl. Plant Sci. 6, e1031 (2018).

32. Lowe, $\mathrm{K}$. et al. Morphogenic regulators baby boom and wuschel improve monocot transformation. Plant Cell 28, 1998-2015 (2016).

33. Richardson, T., Thistleton, J., Higgins, T. J., Howitt, C. \& Ayliffe, M. Efficient Agrobacterium transformation of elite wheat germplasm without selection. Plant Cell Tissue Organ Cult. 119, 647-659 (2014).

34. Doudna, J. A. C. \& Charpentier, E. Genome editing. the new frontier of genome engineering with CRISPR-Cas9. Science 346, 1258096 (2014).

35. Zhang, Z. et al. A multiplex CRISPR/Cas9 platform for fast and efficient editing of multiple genes in Arabidopsis. Plant Cell Rep. 35, 1519-1533 (2016).

36. Liang, Z. et al. Efficient DNA-free genome editing of bread wheat using CRISPR/Cas9 ribonucleoprotein complexes. Nat. Commun. 8, 14261 (2017).

37. Svitashev, S., Schwartz, C., Lenderts, B., Young, J. K. \& Mark Cigan, A. Genome editing in maize directed by CRISPR-Cas 9 ribonucleoprotein complexes. Nat. Commun. 7, 13274 (2016).

38. Andersson, M. et al. Genome editing in potato via CRISPR-Cas9 ribonucleoprotein delivery. Physiol. Plant. 164, 378-384 (2018).

39. Hamada, H. et al. An in planta biolistic method for stable wheat transformation. Sci. Rep. 7, 11443 (2017).

40. Mitter, N. et al. Clay nanosheets for topical delivery of RNAi for sustained protection against plant viruses. Nat. Plants 3, 16207 (2017).

41. Wang, M. et al. Gene targeting by homology-directed repair in rice using a geminivirus-based CRISPR/Cas9 system. Mol. Plant 10, 1007-1010 (2017).

42. Meuwissen, T. H. E., Hayes, B. J. \& Goddard, M. E. Prediction of total genetic value using genome-wide dense marker maps. Genetics 157, 1819-1829 (2001).

43. Cooper, M., Gho, C., Leafgren, R., Tang, T. \& Messina, C. Breeding drought-tolerant maize hybrids for the US corn-belt: discovery to product. J. Exp. Bot. 65, 6191-6204 (2014)

44. Gaffney, J. et al. Industry-scale evaluation of maize hybrids selected for increased yield in drought-stress conditions of the US corn belt. Crop Sci. 55, 1608-1618 (2015).

45. Crain, J., Mondal, S., Rutkoski, J., Singh, R. P. \& Poland, J. Combining high-throughput phenotyping and genomic information to increase prediction and selection accuracy in wheat breeding. Plant Genome 11, 170043 (2018)

46. Hayes, B. J. et al. Accelerating wheat breeding for end-use quality with multi-trait genomic predictions incorporating near infrared and nuclear magnetic resonance-derived phenotypes. Theor. Appl. Genet. 130, 2505-2519 (2017).

47. Buckler, E.S. et al. rAmpSeq: using repetitive sequences for robust genotyping. Preprint at https://doi.org/10.1101/096628 (2016).

48. Steuernagel, B., Witek, K., Jones, J. D. G. \& Wulff, B. B. H. MutRenSeq: a method for rapid cloning of plant disease resistance genes. Methods Mol. Biol. 1659, 215-229 (2017).

49. Arora, S. et al. Resistance gene discovery and cloning by sequence capture and association genetics. Nat. Biotechnol. 37, 139-143 (2019).

50. Kemper, K. E., Bowman, P. J., Pryce, J. E., Hayes, B. J. \& Godd̂ard, M. E. Long-term selection strategies for complex traits using high-density genetic markers. J. Dairy Sci. 95, 4646-4656 (2012).

51. Meyer, R. S. \& Purugganan, M. D. Evolution of crop species: genetics of domestication and diversification. Nat. Rev. Genet. 14, 840-852 (2013).

52. Zsögön, A., Cermak, T., Voytas, D. \& Peres, L. E. P. Genome editing as a tool to achieve the crop ideotype and de novo domestication of wild relatives: case study in tomato. Plant Sci. 256, 120-130 (2017).

53. Renny-Byfield, S. \& Wendel, J. F. Doubling down on genomes: polyploidy and crop plants. Am. J. Bot. 101, 1711-1725 (2014).

54. Leal-Bertioli, S. C. M. et al. Segmental allopolyploidy in action: increasing diversity through polyploid hybridization and homoeologous recombination. Am. J. Bot. 105, 1053-1066 (2018).

55. O'Connor, D. J. et al. Development and application of speed breeding technologies in a commercial peanut breeding program. Peanut Sci. 40, 107-114 (2013).

56. Simmonds, N. W. R. \& Rind, D. The Evolution of the Bananas. (Longmans, London, 1962).

57. Ploetz, R. C. Management of fusarium wilt of banana: a review with special reference to tropical race 4. Crop Prot. 73, 7-15 (2015).

58. Tripathi, J. N. et al. CRISPR/Cas9 editing of endogenous banana streak virus in the B genome of Musa spp. overcomes a major challenge in banana breeding. Commun. Biol. 2, 46 (2019).

59. Naim, F. et al. Gene editing the phytoene desaturase alleles of Cavendish banana using CRISPR/Cas9. Transgenic Res. 27, 451-460 (2018).

60. Ortiz, R. V. D. Factors influencing seed set in triploid Musa spp. L. and production of euploid hybrids. Annu. Bot. 75, 151-155 (1995).

61. Jansky, S. H. et al. Reinventing potato as a diploid inbred line-based crop. Crop Sci. 56, 1412-1422 (2016).

62. Ortiz, R. \& Swennen, R. From crossbreeding to biotechnology-facilitated improvement of banana and plantain. Biotechnol. Adv. 32, 158-169 (2014).

63. Lemmon, Z. H. et al. Rapid improvement of domestication traits in an orphan crop by genome editing. Nat. Plants 4, 766-770 (2018).

64. $\mathrm{Li}, \mathrm{T}$. et al. Domestication of wild tomato is accelerated by genome editing. Nat. Biotechnol. 36, 1160 (2018).

65. Penfield, S. Seed dormancy and germination. Curr. Biol. 27, R874-R878 (2017).

66. Lulsdorf, M. M. \& Banniza, S. Rapid generation cycling of an F2 population derived from a cross between Lens culinaris Medik. and Lens ervoides (Brign.) Grande after aphanomyces root rot selection. Plant Breed. 0, 1-6 (2018).

67. Zheng, Z., Wang, H. B., Chen, G. D., Yan, G. J. \& Liu, C. J. A procedure allowing up to eight generations of wheat and nine generations of barley per annum. Euphytica 191, 311-316 (2013).

68. Hatfield, J. L. \& Prueger, J. H. Temperature extremes: effect on plant growth and development. Weather Clim. Extrem. 10, 4-10 (2015).

69. Draeger, T. \& Moore, G. Short periods of high temperature during meiosis prevent normal meiotic progression and reduce grain number in hexaploid wheat (Triticum aestivum L.). Theor. Appl. Genet. 130, 1785-1800 (2017).

70. Chen, M., Chory, J. \& Fankhauser, C. Light signal transduction in higher plants. Annu. Rev. Genet. 38, 87-117 (2004).

71. Monostori, I. et al. LED lighting - modification of growth, metabolism, yield and flour composition in wheat by spectral quality and intensity. Front. Plant Sci. 9, 605 (2018).

72. Ooi, A. et al. Growth and development of Arabidopsis thaliana under single-wavelength red and blue laser light. Sci. Rep. 6, 33885 (2016).

73. Page, V. \& Feller, U. Selection and hydroponic growth of bread wheat cultivars for bioregenerative life support systems. Adv. Space Res. 52, 536-546 (2013).

74. Asseng, S. et al. Simulated wheat growth affected by rising temperature, increased water deficit and elevated atmospheric $\mathrm{CO}_{2}$. Field Crops Res. 85, 85-102 (2004).

75. Velez-Ramirez, A. I. et al. A single locus confers tolerance to continuous light and allows substantial yield increase in tomato. Nat. Commun. 5, 4549 (2014). 
76. Al-Ismaili, A. M. \& Jayasuriya, H. Seawater greenhouse in Oman: a sustainable technique for freshwater conservation and production. Renew. Sustain. Energy Rev. 54, 653-664 (2016).

77. Liu, W. et al. A novel agricultural photovoltaic system based on solar spectrum separation. Sol. Energy 162, 84-94 (2018).

78. Purugganan, M. D. F. \& Fuller, D. Q. The nature of selection during plant domestication. Nature 457, 843-848 (2009).

79. Xu, Y. Molecular Plant Breeding Ch. 1 (CABI, 2010).

80. Fischer, H. E. Origin of the 'weisse schlesische Rübe' (white Silesian beet) and resynthesis of sugar beet. Euphytica 41, 75-80 (1989).

81. Darwin, C. On the Origin of Species by Means of Natural Selection, or, the Preservation of Favoured Races in the Struggle for Life (J. Murray, 1859).

82. Mendel, G. Experiments in plant hybridization. Verhandlungen des naturforschenden Vereins Brünn (1865); http://www.mendelweb.org/mendel. html

83. Johannsen, W. L. Über Erblichkeit in Populationen und reinen Linien. Eine Beitrag zur Beleuchtung schwebender Selektionsfragen [On heredity in pure lines and populations. A contribution to pending questions of selection]. (Gustav Fischer, Jena, Germany, 1903).

84. Harlan, H.V., Martin, M.L. \& Stevens, H. A study of methods in barley breeding. U.S.D.A. Tech. Bull. 720 (1940).

85. Shull, G. H. What is "heterosis"? Genetics 33, 439-446 (1948).

86. Fisher, R. A. The correlation between relatives on the supposition of Mendelian inheritance. Trans. R. Soc. Edinb. 52, 399-433 (1918).

26 87. East, E. M. \& Jones, D. F. Inbreeding and Outbreeding (Lippincott, 191).

88. Harlan, H. V. \& Pope, M. N. The use and value of backcrosses in small grain breeding. J. Hered. 13, 319-322 (1922).

89. Crabb, A.R. The Hybrid-Corn Makers: Prophets of Planty (Rutgers Univ. Press, 1947).

90. Stadler, L. J. Genetic effects of x-rays in maize. Proc. Natl Acad. Sci. USA 14, 69-75 (1928)

91. Goulden, C.H. Problems in plant selection. in Proceedings of the Seventh International Genetics Congress (Cambridge Univ. Press, 1939).

92. Ortiz, R. et al. High yield potential, shuttle breeding, genetic diversity, and a new international wheat improvement strategy. Euphytica 157, 365-384 (2007).

93. Hull, F. H. Recurrent selection for specific combining ability in corn. J. Am. Soc. Agron. 37, 134-145 (1945)

94. Donald, C. M. The breeding of crop ideotypes. Euphytica 17, 385-403 (1968).

95. Cohen, S. N., Chang, A. C. Y., Boyer, H. W. \& Helling, R. B. Construction of biologically functional bacterial plasmids in vitro. Proc. Natl Acad. Sci. USA 70, 3240-3244 (1973).

96. Helentjaris, T., King, G., Slocum, M., Siedenstrang, C. \& Wegman, S Restriction fragment polymorphisms as probes for plant diversity and their development as tools for applied plant breeding. Plant Mol. Biol. 5, 109-118 (1985).

97. Welsh, J. \& McClelland, M. Fingerprinting genomes using PCR with arbitrary primers. Nucleic Acids Res. 18, 7213-7218 (1990).

98. Akkaya, M. S., Bhagwat, A. A. \& Cregan, P. B. Length polymorphisms of simple sequence repeat DNA in soybean. Genetics 132, 1131-1139 (1992).

99. Kramer, M. G. \& Redenbaugh, K. Commercialization of a tomato with an antisense polygalacturonase gene: the FLAVR SAVR ${ }^{\mathrm{TM}}$ tomato story. Euphytica 79, 293-297 (1994).

100. Lin, J.-J. \& Kuo, J. AFLPTM: a novel PCR-based assay for plant and bacterial DNA fingerprinting. Focus 17, 66-70 (1995).

101. Arabidopsis Genome Initiative. Analysis of the genome sequence of the flowering plant Arabidopsis thaliana. Nature 408, 796-815 (2000).

102. Jander, G. et al. Arabidopsis map-based cloning in the post-genome era Plant Physiol. 129, 440-450 (2002).
103. Bibikova, M., Golic, M., Golic, K. G. \& Carroll, D. Targeted chromosomal cleavage and mutagenesis in Drosophila using zinc-finger nucleases. Genetics 161, 1169-1175 (2002)

104. International Rice Genome Sequencing Project. The map-based sequence of the rice genome. Nature 436, 793-800 (2005).

105. Bernardo, R. Y. \& Yu, J. Prospects for genomewide selection for quantitative traits in maize. Crop Sci. 47, 1082-1090 (2007).

106. Schnable, P. S. et al. The B73 maize genome: complexity, diversity, and dynamics. Science 326, 1112-1115 (2009).

107. Mahfouz, M. M. et al. De novo-engineered transcription activator-like effector (TALE) hybrid nuclease with novel DNA binding specificity creates double-strand breaks. Proc. Natl Acad. Sci. USA 108, 2623-2628 (2011).

108. Jinek, M. et al. A programmable dual-RNA-guided DNA endonuclease in adaptive bacterial immunity. Science 337, 816-821 (2012)

109. The International Wheat Genome Sequencing Consortium. Shifting the limits in wheat research and breeding using a fully annotated reference genome. Science 361, eaar7191 (2018).

110. Collard, B. C. Y. et al. Revisiting rice breeding methods-evaluating the use of rapid generation advance (RGA) for routine rice breeding. Plant Prod. Sci. 20, 337-352 (2017).

111. Tanaka, J., Hayashi, T. \& Iwata, H. A practical, rapid generationadvancement system for rice breeding using simplified biotron breeding system. Breed. Sci. 66, 542-551 (2016).

112. Nagatoshi, Y. \& Fujita, Y. Accelerating soybean breeding in a $\mathrm{CO}_{2}{ }^{-}$ supplemented growth chamber. Plant Cell Physiol. 60, 77-84 (2019).

113. Rizal, G. et al. Shortening the breeding cycle of sorghum, a model crop for research. Crop Sci. 54, 520-529 (2014).

114. Ashraf, M. \& Hafeez, M. Thermotolerance of pearl millet and maize at early growth stages: growth and nutrient relations. Biol. Plant. 48, 81-86 (2004).

115. Li, H., Xu, Z. \& Tang, C. Effect of light-emitting diodes on growth and morphogenesis of upland cotton (Gossypium hirsutum L.) plantlets in vitro. Plant Cell Tissue Organ Cult. 103, 155-163 (2010).

116. Hale, A. L., White, P. M., Webber, C. L. III \& Todd, J. R. Effect of growing media and fertilization on sugarcane flowering under artificial photoperiod. PLoS One 12, e0181639 (2017).

\section{Açknowledgements}

We thank V. Korzun and C. Uauy for feedback on an earlier draft of this manuscript, T. Draeger for discussions, and T. Florio (www.flozbox.com/Science.illustrated) for the artwork. B.W. was supported by the Biotechnology and Biological Sciences Research Council cross-institute strategic programme Designing Future Wheat (BB/P016855/1) and the 2Blades Foundation, M.T. by King Abdullah University of Science \& Technology, L.T.H. by an Australian Research Council Early Career Discovery Research Award (DE170101296), C.G. by the National Natural Science Foundation of China (31788103), and S.L.-B. by the Peanut Foundation.

\section{Competing interests}

H.R. is an employee of Intergrain, which produces and markets plant breeding materials.

\section{Additional information}

Supplementary information is available for this paper at https://doi.org/10.1038/ s41587-019-0152-9.

Reprints and permissions information is available at www.nature.com/reprints.

Correspondence should be addressed to L.T.H. or B.B.H.W.

Publisher's note: Springer Nature remains neutral with regard to jurisdictional claims in published maps and institutional affiliations.

(C) Springer Nature America, Inc. 2019 


\section{QUERY FORM}

\begin{tabular}{|l|c|}
\hline \multicolumn{2}{|c|}{ Nature Biotechnology } \\
\hline Manuscript ID & [Art. Id: 152] \\
\hline Author & Lee T. Hickey \\
\hline
\end{tabular}

\section{AUTHOR:}

The following queries have arisen during the editing of your manuscript. Please answer by making the requisite corrections directly in the e.proofing tool rather than marking them up on the PDF. This will ensure that your corrections are incorporated accurately and that your paper is published as quickly as possible.

\begin{tabular}{|c|c|}
\hline Query No. & Nature of Query \\
\hline Q1: & Corresponding author emails correct as added? \\
\hline Q2: & Duplicate refs. (the original 116 and 118) have been deleted and references renumbered; please check. \\
\hline Q3: & $\begin{array}{l}\text { Author surnames have been highlighted - please check these carefully and indicate if the first name or surname } \\
\text { have been marked up incorrectly. Please note that this will affect indexing of your article, such as in PubMed. }\end{array}$ \\
\hline Q4: & $\begin{array}{l}\text { Please note that the eproof should be amended in only one browser window at any one time, otherwise changes } \\
\text { will be overwritten. }\end{array}$ \\
\hline Q5: & $\begin{array}{l}\text { Please explain in the Fig. } 1 \text { legend what is shown in the left vs right columns, the color code for the dates, and } \\
\text { the significance of the items that are boxed vs. unboxed. }\end{array}$ \\
\hline Q6: & $\begin{array}{l}\text { "Genomic selection applied in maize" and the associated(?) chromatin image have been moved to place them in } \\
\text { chronological order; ok? }\end{array}$ \\
\hline Q7: & Units correct as added for field or greenhouse generation time? \\
\hline Q8: & Please define PAR in Table 1. \\
\hline Q9: & Spell out B:R \\
\hline Q10: & Generations 7 and 8 in $2 \mathrm{a}$ appear identical; please check. \\
\hline Q11: & Title ok as added for Fig. 4? \\
\hline Q12: & Image changed from "double haploid" to match legend and main text; please advise which term is preferred. \\
\hline Q13: & "To reduce the costs, one option is" ok as edited? \\
\hline Q14: & Please define $\mathrm{x}$ in " $4 \mathrm{x}$ by $2 \mathrm{x}$ "; or, if they are ploidy numbers, substitute " $\mathrm{n}$ ". \\
\hline Q15: & Please clarify "imbibed at low temperature". \\
\hline Q16: & GA3 ok as defined in $5 a ?$ \\
\hline Q17: & $\begin{array}{l}\text { Minus sign has been deleted from the subscript of the phosphate; ok? Or indicate with a superscript; but would } \\
\text { need to have the correct charge ( } 3 \text { - for phosphate ion itself - but that doesn't reflect actual species present at } \\
\text { soil pH. Pi could be used for generic inorganic phosphate if preferred, but may be less idiomatic.) }\end{array}$ \\
\hline Q18: & British "glasshouse" changed to American "greenhouse" throughout (NBT uses US English); please confirm. \\
\hline
\end{tabular}




\section{QUERY FORM}

\begin{tabular}{|l|c|}
\hline \multicolumn{2}{|c|}{ Nature Biotechnology } \\
\hline Manuscript ID & [Art. Id: 152] \\
\hline Author & Lee T. Hickey \\
\hline
\end{tabular}

\section{AUTHOR:}

The following queries have arisen during the editing of your manuscript. Please answer by making the requisite corrections directly in the e.proofing tool rather than marking them up on the PDF. This will ensure that your corrections are incorporated accurately and that your paper is published as quickly as possible.

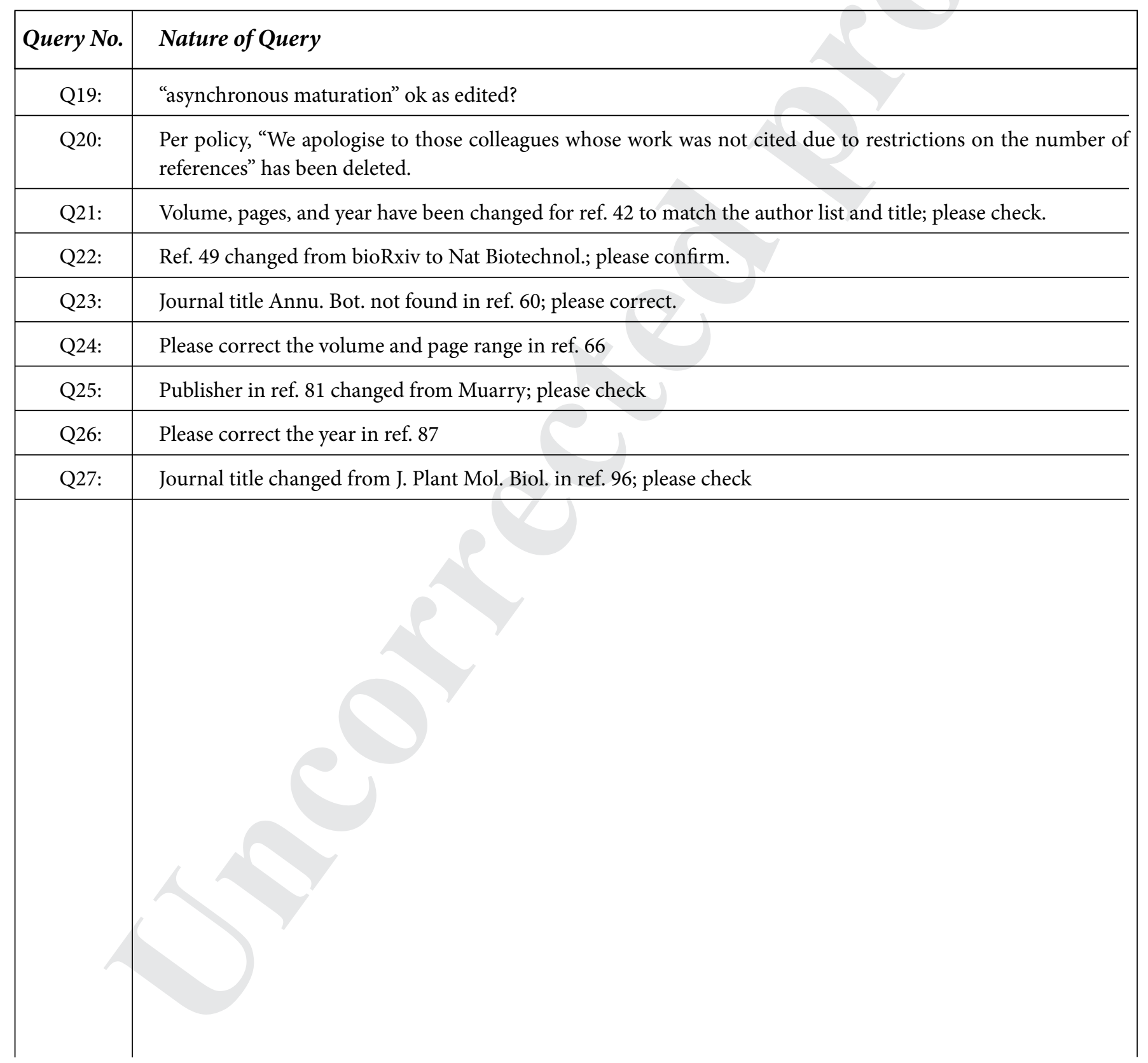

